\title{
Divergence in the Socioeconomic Development Paths of Hungary and Slovakia
}

\author{
Zoltán Bartha This study aims to provide a comparative analysis of \\ University of Miskolc socioeconomic development in Slovakia and \\ E-mail: Hungary. For this purpose, we use the State of the \\ zolib@hu.inter.net Future Index (SOFI) to measure and forecast the \\ socioeconomic well-being of both the countries \\ Klára Szita Tóthné from 1995 to 2015. The SOFI methodology has \\ University of Miskolc many characteristics that are in line with the 2009 \\ E-mail: Stiglitz-Sen-Fitoussi report. We find that during \\ regszita@uni.miskolc.hu 1995-1999, Slovakia had a higher overall SOFI total, \\ signifying a higher level of well-being; subsequently, \\ however, Hungary pulled ahead between 1999 and \\ 2005, after which Slovakia overtook Hungary yet \\ again. Our predictions suggest that Slovakia will \\ continue to pull ahead in the 2015-2025 period. The \\ areas where Hungary has scope for considerable \\ improvement are life expectancy, GDP per capita, \\ renewable energy resources and $\mathrm{CO}_{2}$ emission and \\ Keywords: government debt. In some areas, both countries \\ development path, perform poorly: level of corruption and \\ Hungary, demographic trend. However, Hungary seems to \\ State of the Future Index, have an advantage in $R \& D$ expenditure, \\ Slovakia unemployment level and voter turnout.
}

\section{Introduction}

The development paths taken by the Central and Eastern European countries during and after the transition period have been subject to substantial research. In this regard, a comparison of Slovakia and Hungary seems justifiable in many ways: the two countries share a common history and similar cultural background, although there are notable differences as well; for example, Slovakia had to create a new institutional system after the dissolution of Czechoslovakia. Moreover, the countries are seemingly on two very different development paths.

If we look at the PPP GDP per capita of both the countries, in 1995, Hungary was leading by around 14\%; however, by 2015, Slovakia overtook Hungary, and 
gained an advantage close to $13 \%$. During this period, the PPP GDP per capita of Hungary rose by a yearly average of $4.3 \%$, while that of Slovakia was $5.7 \%$ (IMFWEO). Nevertheless, the development of a country cannot simply be described with per capita GDP data. The human development index (HDI), a composite index maintained by the UN Development Programme, combines variables measuring educational achievements, life expectancy and per capita income. A comparison of HDI between Hungary and Slovakia unfolds a slightly different picture: in 1990, Hungary's HDI was 0.701, while Slovakia's was 0.747 ; by 2000, the two countries achieved close to even scores (0.774 and 0.776); in 2013, however, Slovakia had an advantage again (0.818 vs. 0.830$)$. While Hungary's per capita GDP developed at a slower pace, the country's HDI grew faster between 1990 and 2013 (UNDP).

Using an even larger number of indicators (16 in total), Sikulová and Frank (2013) conducted a study among 10 Central and Eastern European countries that joined the EU between 2004 and 2007. All countries were ranked according to the indicator values, and the final score of every country was based on these rankings. Sikulová and Frank organised the various indicators into three groups ('trinity'): welfare/equality; innovation/growth/competitiveness; and macroeconomic stability. They found that Hungary outperformed Slovakia in the welfare/equality dimension (thanks to its lower unemployment level and higher expenditure on social protection as a percentage of GDP). Slovakia, on the other hand, performed better in both macroeconomic stability (especially in public and private indebtedness and price stability) and innovation/growth/competitiveness (the largest difference can be detected in the case of GDP growth rate) (Sikulová-Frank 2013, pp. 8-9). According to the cluster analysis prepared by the authors, Hungary and Slovakia fall into two different clusters, with Hungary focusing on welfare and Slovakia on growth stability (Sikulová-Frank 2013, pp. 11).

In this study, we use the State of the Future Index (SOFI) to assess the socioeconomic development paths of Hungary and Slovakia between 1995 and 2015. Furthermore, since the index was designed with the purpose of measuring future progress, we also derive a possible development path for 2015-2025.

\section{Measuring socioeconomic development}

Since the Stiglitz-Sen-Fitoussi report was published in 2009, renewed efforts were made to accurately measure different aspects of well-being. The report itself, amongst others, provided the following notable suggestions:

- shift emphasis from measuring economic production to measuring people's well-being;

- emphasise on the sustainability of the level of well-being, which also implies that stocks of capital (natural, physical, human and social) that are passed on to future generations will have to be accurately measured as well; 
- rather than purely measuring the value of production, focus on capturing quality change (which is especially important in case of services, e.g. healthcare);

- find a better way of measuring government output, and especially capture productivity change;

- focus more on household consumption and income, but consider it jointly with wealth, because spending current wealth on consumption goods increases current well-being at the expense of future well-being;

- more prominence should be given to the distribution of income and wealth;

- attempts should be made to measure non-market activities and leisure;

- finally, well-being should be approached from a multi-dimensional perspective, namely, at least the following eight aspects need to be focused on:

- material living standards (income, consumption and wealth);

- health;

- education;

- personal activities including work;

- political voice and governance;

- social connections and relationships;

- environment (present and future conditions);

- insecurity, of an economic as well as a physical nature (Stiglitz-Sen-Fitoussi 2009).

Attempts to measure socioeconomic development can be dated back to the 1950s and 1960s (Gáspár 2013). Gáspár (2013) presents a comprehensive summary on the measurement methods and indices developed over the decades. He distinguishes between two main measures of socioeconomic development/performance: objective and subjective.

The objective measures use statistical data. Here are some examples of such measurement methods:

- adjusting the GDP with additional costs: net economic welfare (1972), index of sustainable economic welfare (1989), genuine progress indicator (1995);

- composite indices: physical quality of life index (1979), HDI (1990), life product index (1992), basic and advanced quality of life index (1995);

- models based on multivariate statistical analysis;

- other measures: weighted index of social progress, happy planet index, ease of doing business index, globalisation index and so on. (Gáspár 2013, pp. 78-79).

The subjective measures apply a qualitative approach to assess well-being, concentrating on the feelings and subjective well-being of people. This second type of measures include:

- cognitive measurements: Cantril's ladder or satisfaction with life scale;

- measuring emotions: happiness measurement, positive-negative feelings, U-index, Gallup world poll, European social survey and so on. (Gáspár 2013, pp. 82-85).

Regional Statistics, Vol 5, No 2. 2015: 125-143; DOI: 10.15196/RS05207 


\section{The State of the Future Index}

The State of the Future Index (SOFI) was developed by Theodore J. Gordon and Jerome C. Glenn within The Millennium Project (Glenn-Florescu 2015). Using the current methodology, the SOFI was first published in 2001 (Glenn-Gordon 2001). Back then, only the global value was calculated. Thereafter, a number of regional- and country-level SOFIs have appeared. The current study is based on a SOFI calculation conducted in 2014-15 within a project funded by the International Visegrad Fund (Bartha-Tóthné 2015, Klinec 2015).

The SOFI is a composite index; its standard version combines the effects of 26 socioeconomic indicators. All of the indicators are objective measures if we use Gáspár's classification presented above, although some of them were created by polling experts (e.g. the corruption perception index or the level of freedom). One of the greatest advantages of SOFI is that most aspects highlighted by the Stiglitz-SenFitoussi report are reflected by at least one of its indicators:

- emphasis on sustainability and stocks of capital: forest lands or R\&D expenditures;

- capturing quality: life expectancy or corruption perception;

- income distribution: poverty headcount or literacy rate;

- the eight dimensions

- material living standards: per capita GDP;

- health: infant mortality, number of physicians or life expectancy;

- education: literacy rate or secondary school enrolment;

- personal activities including work: not included, although the number of internet users may be moderately related to it;

- political voice and governance: people voting in elections or freedom level;

- social connections and relationships: not included, although the number of seats held by women in the national parliament may be moderately related to it;

- environment: $\mathrm{CO}_{2}$ emission or energy efficiency;

- insecurity: number of homicides, unemployment level or number of terrorist incidents.

It is worth mentioning that some of the indicators are do not accurately reflect the given focus area. The SOFI could definitely be improved by selecting indicators that better measure its global challenges. In this manner, it would be even more in line with the principles of the Stiglitz-Sen-Fitoussi report.

The other great advantage of the SOFI is that it was designed to enhance future orientation. The future orientation of SOFI is caused by two factors. First, the individual indicators were selected because they are believed to be accurate measures of the global challenges which, according to The Millennium Project, will play a very important role in the future of our societies. Second, part of the SOFI methodology involves the creation of future indices, typically calculated 10 years ahead. 
While the Washington DC-based Millennium Project focuses on the global SOFI, its regional and country level nodes calculate regional and national SOFIs. There are two types of national SOFIs: National Focus and National Comparison SOFI. Some or all of the indicators used to calculate the National Focus SOFI are different from the ones used in the standard, global index. The main aim of the National Focus SOFI is to include indicators that are most relevant for the current and future development of a single given country. It can even happen that the very same indicator is interpreted differently in the National Focus and global SOFI; for example, while population growth increases the value of the standard index, in an overpopulated country, it can be set to decrease it.

The National Comparison SOFI includes the same indicators as the global one. Since it is calculated with identical contents, its primary advantage is that it is comparable to any standard SOFI. However, the disadvantage is that it may include indicators that are not relevant for a given region or country (e.g. the prevalence of HIV can be an important global indicator and is extremely important for Africa, but much less so for the Central and Eastern European region).

For our analysis, we have used the National Comparison SOFI. For a more comprehensive analysis, a specific Central and Eastern European SOFI may be developed in the future. The National Comparison SOFI is calculated in eight steps, each of which has been described below.

\section{Step 1: Identifying global challenges}

In a multi-phase attempt, The Millennium Project had derived 15 global challenges between 1996 and 1999. All phases involved several hundred experts, futurists and decision-makers from around the world; in total, more than 4,000 experts were involved in the SOFI process since 1996. In the first phase lasting 1996-97, 182 issues were collected which then were summarised into 15 global issues. The next phase took place in 1997-98, during which 180 opportunities were gathered and again synthesised into 15 global opportunities. During 1998-99, the global issues and opportunities were combined and 15 global challenges were derived that currently form the basis of SOFI. The 15 global challenges are described in detail at https://themp.org/. In this study, we only list them in the order they were originally compiled. Although the challenges were derived much earlier than the Stiglitz-SenFitoussi report was released, their contents and main messages are quite well matched.

1. Sustainable development and climate change: How can sustainable development be achieved for all while addressing global climate change?

2. Clean water: How can everyone have sufficient clean water without conflict?

3. Population and resources: How can population growth and resources be brought into balance?

4. Democratisation: How can genuine democracy emerge from authoritarian regimes?

Regional Statistics, Vol 5, No 2. 2015: 125-143; DOI: 10.15196/RS05207 
5. Global foresight and decision-making: How can decision-making be enhanced by integrating improved global foresight during unprecedented accelerating change?

6. Global convergence of IT: How can the global convergence of information and communications technologies work for everyone?

7. Rich-poor gap: How can ethical market economies be encouraged to help reduce the gap between the rich and poor?

8. Health issues: How can the threat of new and re-emerging diseases and immune micro-organisms be reduced?

9. Education: How can education make humanity more intelligent, knowledgeable and wise enough to address its global challenges?

10. Peace and conflict: How can shared values and new security strategies reduce ethnic conflicts, terrorism and the use of weapons of mass destruction?

11. Status of women: How can the changing status of women help improve the human condition?

12. Transnational organised crime: How can transnational organised crime networks be prevented from becoming more powerful and sophisticated global enterprises?

13. Energy: How can growing energy demands be met safely and efficiently?

14. Science and technology: How can scientific and technological breakthroughs be accelerated to improve the human condition?

15. Global ethics: How can ethical considerations become more routinely incorporated into global decisions?

\section{Step 2: Selecting the indicators}

During 2000-2001, experts from The Millennium Project participated in a Delphi study in which those indicators were selected that are most suited to measure progress in the 15 global challenges. To calculate the global and the National Comparison SOFI, the following 26 indicators are currently used:

1. $\mathrm{CO}_{2}$ emissions (percent of global emissions);

2. Electricity production from renewable sources, excluding hydroelectric (percent of total);

3. Food availability (Kcalories/day per capita);

4. Forest lands (percent of national land area);

5. Freedom level (Freedom House country scores; $1=$ completely free; $7=$ completely not free);

6. GDP per capita (2,000 USD PPP);

7. GDP per unit of energy use (2,000 USD PPP per $\mathrm{kg}$ of oil equivalent);

8. Homicides, intentional (per 100,000 population);

9. Infant mortality (deaths per 1,000 live births);

10. Internet users (per 1,000 population);

Regional Statistics, Vol 5, No 2. 2015: 125-143; DOI: 10.15196/RS05207 
11. Levels of corruption (Transparency International; Corruption Perception Index);

12. Life expectancy at birth (years);

13. Literacy rate, adult total (percent of people aged 15 and above);

14. Number of refugees displaced from the country (percent of national population);

15. People killed or injured in terrorist attacks (percent of national population);

16. People voting in elections (percent of national population of voting age);

17. Physicians (per 1,000 people);

18. Population growth (annual \%);

19. Population lacking access to improved water sources (percent of national population);

20. Poverty headcount ratio at $\$ 1.25$ a day (PPP) (percent of national population);

21. Prevalence of HIV (percent of national population);

22. R\&D expenditures (percent of GDP);

23. School enrolment, secondary (percent gross);

24. Seats held by women in national parliament (percent of all national members);

25. General government gross debt (percent of GDP);

26. Unemployment (percent of national labour force).

\section{Step 3: Setting up the database}

For the analysis, variable values for 20 years between 1995 and 2013-14 were collected. Missing data were replaced using interpolation. The following sources were used to set up our database:

- World Bank's World Development Indicators (WDI);

- Freedom House;

- International Monetary Fund - World Economic Outlook (IMF-WEO);

- Pardee Center for International Futures at the University of Denver International Futures forecasting system (IF);

- Hungarian National Election Office (HNEO);

- International Institute for Democracy and Electoral Assistance (IDEA);

- World Health Organisation (WHO);

- US Energy Information Administration (EIA).

To ensure maximum compatibility, we chose sources where both the Hungarian and the Slovakian time series were available.

\section{Step 4: Forecasting the indicators}

The indicators were extrapolated to the 2015-25 period using the database containing 20 -year time series data. Mostly linear trend was used for the extrapolation. If external forecasts were available for a series, those were used instead of own extrapolation. Where the indicator was very close to the extreme value and it showed a stable pattern, the last (2014) actual value was held constant and carried over for the entire 2015-25 period. Table 1 shows what method was used to obtain future indicator values in case of all 26 variables.

Regional Statistics, Vol 5, No 2. 2015: 125-143; DOI: 10.15196/RS05207 
Characteristics of the 26 indicators

\begin{tabular}{c|l|r|r|r|r}
\hline Indicator & \multicolumn{1}{|c|}{ Extrapolation } & WeighT & Worst & Best & Type \\
\hline 1 & Linear trend & 7.82 & 10.00 & 0.00 & bad \\
2 & Linear trend & 8.05 & 0.05 & 20.52 & good \\
3 & External: IF & 7.08 & 2205.00 & 3525.00 & good \\
4 & Linear trend & 7.21 & 20.63 & 40.53 & good \\
5 & Last actual value held constant & 7.52 & 7.00 & 1.00 & bad \\
6 & External till 2019: IMF, then linear trend & 7.50 & 5491.00 & 44833.33 & good \\
7 & Linear trend & 8.00 & 2.51 & 26.00 & good \\
8 & Linear trend & 6.92 & 14.66 & 1.06 & bad \\
9 & External: IF & 7.01 & 89.00 & 2.60 & bad \\
10 & Logarithmic trend & 7.90 & 5.23 & 927.00 & good \\
11 & External: IF & 8.57 & 3.31 & 6.15 & good \\
12 & External: IF & 7.14 & 65.05 & 81.00 & good \\
13 & External: IF & 7.45 & 78.87 & 100.00 & good \\
14 & Last actual value held constant & 6.93 & 10.00 & 0.00 & bad \\
15 & Last actual value held constant & 7.66 & 0.10 & 0.00 & bad \\
16 & Last actual value held constant & 7.19 & 30.00 & 84.30 & good \\
17 & Linear trend & 7.50 & 1.46 & 4.30 & good \\
18 & External: IF & 7.27 & -0.60 & 2.00 & good \\
19 & Last actual value held constant & 8.33 & 30.00 & 0.00 & bad \\
20 & External: IF & 7.84 & 26.49 & 0.00 & bad \\
21 & External: IF & 5.97 & 1.91 & 0.01 & bad \\
22 & External till 2020: EU strategy, & & & & \\
& then constant & 8.63 & 0.46 & 4.00 & good \\
23 & External: IF & 8.09 & 59.15 & 103.70 & good \\
25 & Linear trend & 6.78 & 6.86 & 30.20 & good \\
26 & External till 2019: IMF, then linear trend & 6.79 & 86.36 & 7.58 & bad \\
& & 8.28 & 19.46 & 3.90 & bad
\end{tabular}

Source: the authors.

\section{Step 5: Standardising the indicator values}

Because of the different orders of magnitude, every indicator has to be rescaled to a $0-1$ scale before the index is calculated. The rescaling is done with the help of the worst and best values provided by The Millennium Project, and Table 1 contains them. Whether the best value is higher or lower than the worst one depends on whether the given indicator is a 'good' or 'bad' one (last row of Table 1). We differentiate between 'good' and 'bad' indicators based on the direction of change that is needed if we want them to improve: an improvement of a 'good' indicator means its value needs to increase, while a 'bad' indicator improves if its value decreases.

The formula used for rescaling is very simple: (Indicator value - Worst)/(Best Worst).

Regional Statistics, Vol 5, No 2. 2015: 125-143; DOI: 10.15196/RS05207 


\section{Step 6: Assigning weights to the rescaled figures}

Based on the Delphi analysis carried out by The Millennium Project, weights are estimated for every indicator (see column 3 of Table 1). The rescaled values are multiplied by these weights.

\section{Step 7: Calculating the baseline SOFI}

For every year in the 1995-2025 period, an indicator total is calculated by summing up all 26 rescaled and weighted indicator values. The total shows whether the 26 indicators combined improved (increasing total) or worsened (decreasing total) over the period. The baseline SOFI is calculated by choosing a year as a reference (2014 in our analysis), and then dividing all indicator totals with the indicator total of the reference year. The baseline SOFI of the reference year is 1; if this value goes above 1 in the period after the reference year, this implies that the overall socioeconomic conditions improved in the country.

\section{Step 8: Trend impact analysis}

It may turn out that the indicator values change very differently from what is expected based on the trend calculations. In that case, the SOFI will also be different from the baseline version. The Millennium Project developed a method based on expert opinions. This method is used to highlight possible areas where there is likely to be a deviation from the trend.

Since the trend impact analysis suggested by The Millennium Project is extremely time and energy consuming, we adopted a simplified version of the method. We used three different scenarios for an indicator: optimistic, baseline (extrapolated from the time series) and pessimistic. We invited experts and asked them to assess the realistic value of the indicator in these three scenarios (e.g. in case of per capita GDP, one of our experts may suggest 17,000 for the optimistic scenario and 13,000 for the pessimistic one; there is no need to assign a value to the baseline version, since it is already calculated). It is also the task of the experts to assess the likelihood of a scenario to come true (e.g. one of our experts mentions a number of events that might occur and will lead to the positive scenario, then he predicts the likelihood of the occurrence of these events - let us say $20 \%$; the same has to be done with the positive scenario, and a likelihood has to be assigned to the baseline as well).To simplify the task, some indicators were omitted from this process (because they either seemed to be very stable or had less importance in this region). Thus, our experts finally had to assess 17 indicators (Kolos 2015).

The trend impact analysis adds an extra layer to the analysis of the socioeconomic development paths. It may highlight the critical areas. Moreover, it can call for attention to those indicators whose values could be significantly improved if certain circumstances arise. Thirteen experts participated in the Hungarian simplified trend

Regional Statistics, Vol 5, No 2. 2015: 125-143; DOI: 10.15196/RS05207 
analysis, and ten in the Slovakian one. The Hungarian experts were all involved in futures research, mainly coming from the field of social sciences, while most of the Slovakian experts were economists.

\section{Baseline SOFI for Hungary and Slovakia}

The baseline SOFI (Figure 1) suggests that the development trends of Hungary and Slovakia were very different over the 1995-2014 period. Hungary's socioeconomic performance increased dynamically in the 1995-2001 period, and by 2001, the SOFI reached $93 \%$ of its 2014 value. After 2001, however, the pace of development slowed down and there was even a slight decrease in the early 2010s. On the other hand, the socioeconomic performance of Slovakia stagnated or shrank until 2001, which was followed by a massive increase during 2001-2008. The 2008 crisis hit Slovakia harder than Hungary; however, the recovery process was also quicker. Our trend analysis suggests that Slovakia will continue to slowly pull ahead of Hungary in the next ten years.

It is hard not to find a connection between economic policy reforms and SOFI changes in these two countries. Hungary went through a number of rigid reforms in 1990-1995, after which there was a dynamic improvement in the SOFI. Slovakia's reforms began after the 1998 elections brought in a new government and the dynamic SOFI change followed from 2001. The effects of economic policy reforms on the SOFI, however, need further analysis. The reforms carried out in the two countries often involved changes in the structure of government expenditures (e.g. spending less on the poor, healthcare or education) which negatively affect the SOFI. Thus, the dynamic improvement can partially be caused by a recovery from the initial negative budgetary shock.

Figure 1

Baseline SOFI for Hungary and Slovakia (Reference year: 2014)

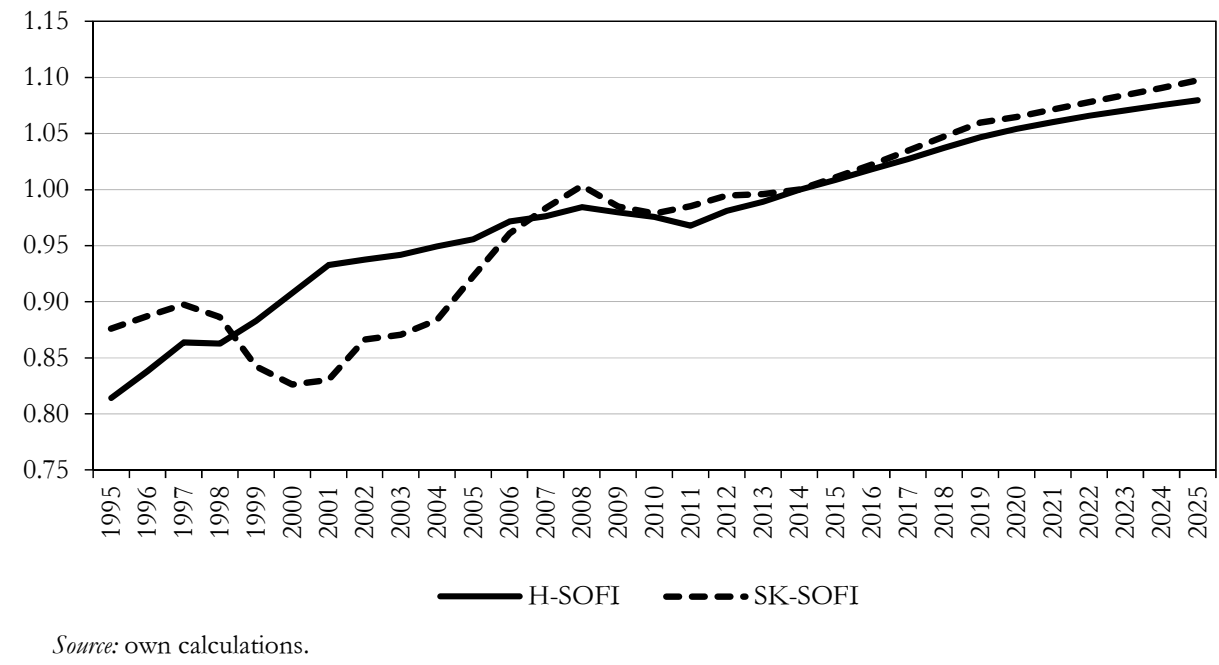

Regional Statistics, Vol 5, No 2. 2015: 125-143; DOI: 10.15196/RS05207 
Figure 2 shows how the SOFI totals (not divided by the total of the reference year) changed during the period. The SOFI totals depict a similar picture to what we observed in case of the HDI in the Introduction. Slovakia begins from a higher level; however, subsequently, Hungary catches up and is ahead between 1999 and 2005. Slovakia pulls ahead again from then on, and according to our extrapolations, will continue to offer a better socioeconomic environment to its citizens in the 2015-2025 period as well. Again, the SOFI totals suggest that Slovakia is on a better socioeconomic development path.

Figure 2

SOFI totals for Hungary and Slovakia

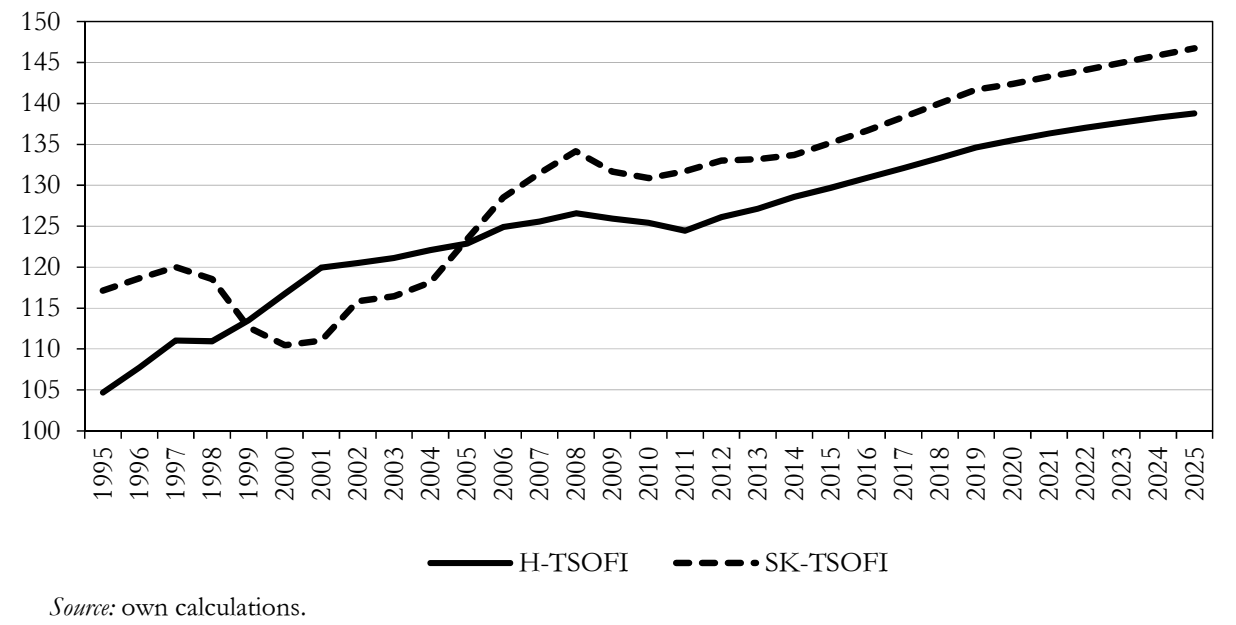

\section{Discussion of SOFI components}

The $\mathrm{CO}_{2}$ emission (indicator 1) has been decreasing in both countries as a percentage of the global emission. Regulations helped in getting the emission of greenhouse gases under control $\left(\mathrm{CO}_{2}\right.$ quota trade, support for renewable resources), but it is mostly influenced by the energy mix of the countries. The absolute values differ significantly in the two countries, because of the energy mix (Table 2), and also thanks to differences in the volume of energy and industrial production as well as in population size. The difference in $\mathrm{CO}_{2}$ emission between the two countries will remain in the future, because of the different size and structure of the two economies. Both countries spend a considerable amount of money on decreasing the emission: Hungary spends 519 USD/capita (ranked 54 among 147 countries), while the value for Slovakia is 640 USD/capita (rank: 43) (Andersen 2015). 
Primary energy production by resources 2013

Table 2

\begin{tabular}{l|c|c}
\multicolumn{1}{c}{ Type } & Hungary & Slovakia \\
\hline Solid & 1,611 & 584.3 \\
Crude oil & 582 & 9.7 \\
Natural gas (liquid) & 279 & 2.7 \\
Natural gas & 1,543 & 104 \\
Nuclear & 3,976 & 4,106 \\
Renewable & 2,074 & 1,466
\end{tabular}

Source: Eurostat.

The yearly $\mathrm{CO}_{2}$ emission was 62.48 million tons in Hungary and 43.2 million tons in Slovakia in 2012. Although their respective share in the global emission has been decreasing, in case of Hungary, the trend might change according to our experts. If Hungary wants to become the most industrialised nation in Europe (a long-term goal put forward by the Hungarian government after 2014), then Hungary's share might increase in the future (Figure 3).

Figure 3

\section{$\mathrm{CO}_{2}$ emission as a percentage of global emission and projection in Slovakia and Hungary}
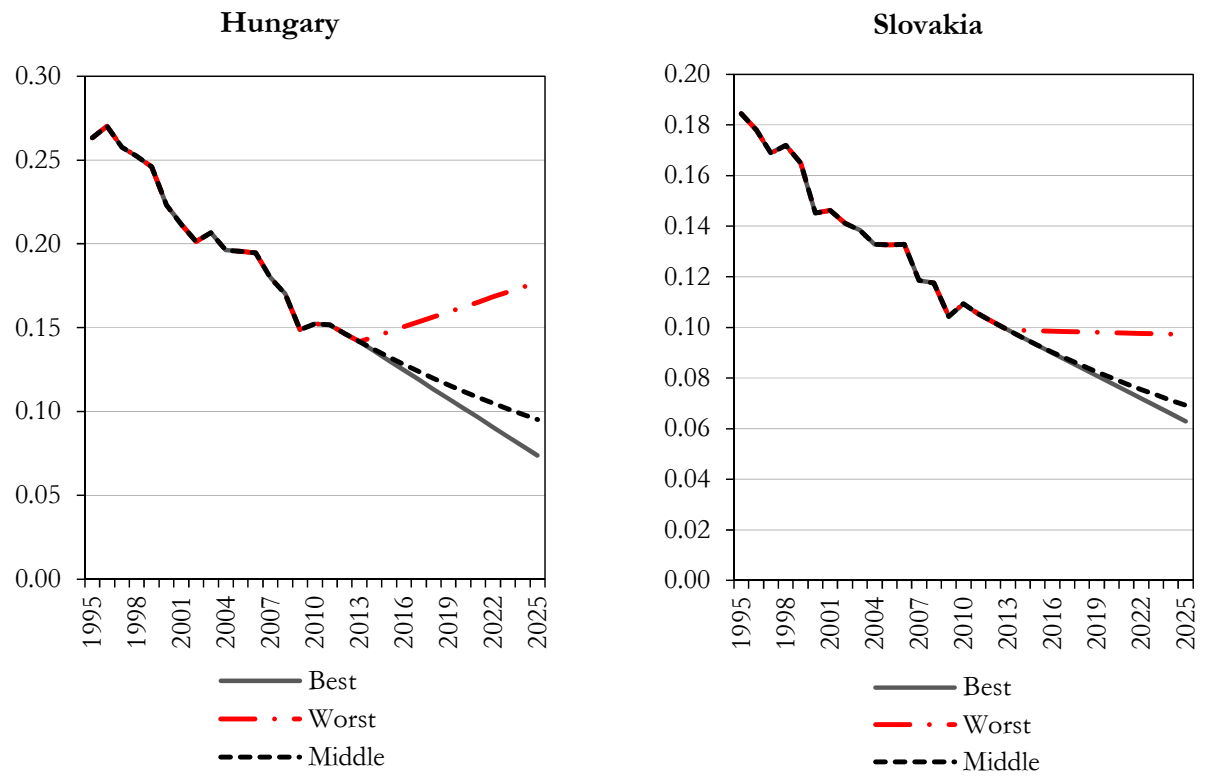

Source: WDI and own calculations. 
The main way of decreasing $\mathrm{CO}_{2}$ emission is to increase the share of renewables (indicator 2) in the energy mix. The share of renewable energy sources from the total electricity production is much lower in Hungary than in Slovakia. According to the energy strategy of the two countries, by 2025, the share of renewables from electricity production will have to be between 6 and 9 percent in Hungary, and between 9 and 16.5 percent in Slovakia (Figure 4). The key objectives of Slovakia's energy policy are increasing efficiency, reducing demand for energy, reducing dependence on energy imports, expanding the use of nuclear power and increasing the share of renewable sources (MoES 2014). The goal of the Hungarian Energy Strategy is similar. It is necessary to change the Hungarian energy structure by 2030 by achieving the following objectives: energy efficiency measures spanning the entire supply and consumption chain; increasing the share of low $\mathrm{CO}_{2}$-intensive electricity generation based primarily on renewable sources of energy (waste to energy); promoting renewable and alternative methods of heat generation; and increasing the share of low $\mathrm{CO}_{2}$-emission modes of transport. The Energy Strategy envisages six energy mix scenarios and proposes the Nuclear-Coal-Green scenario as recommended in the future (NES, 2030). There is scope for further and faster development, as Hungary has significant geothermal potential (Árpási 2003) and for industrial use, the energy intensity is increasing (Kádárné 2013).

\section{Electricity production from renewable energy}

Figure 4
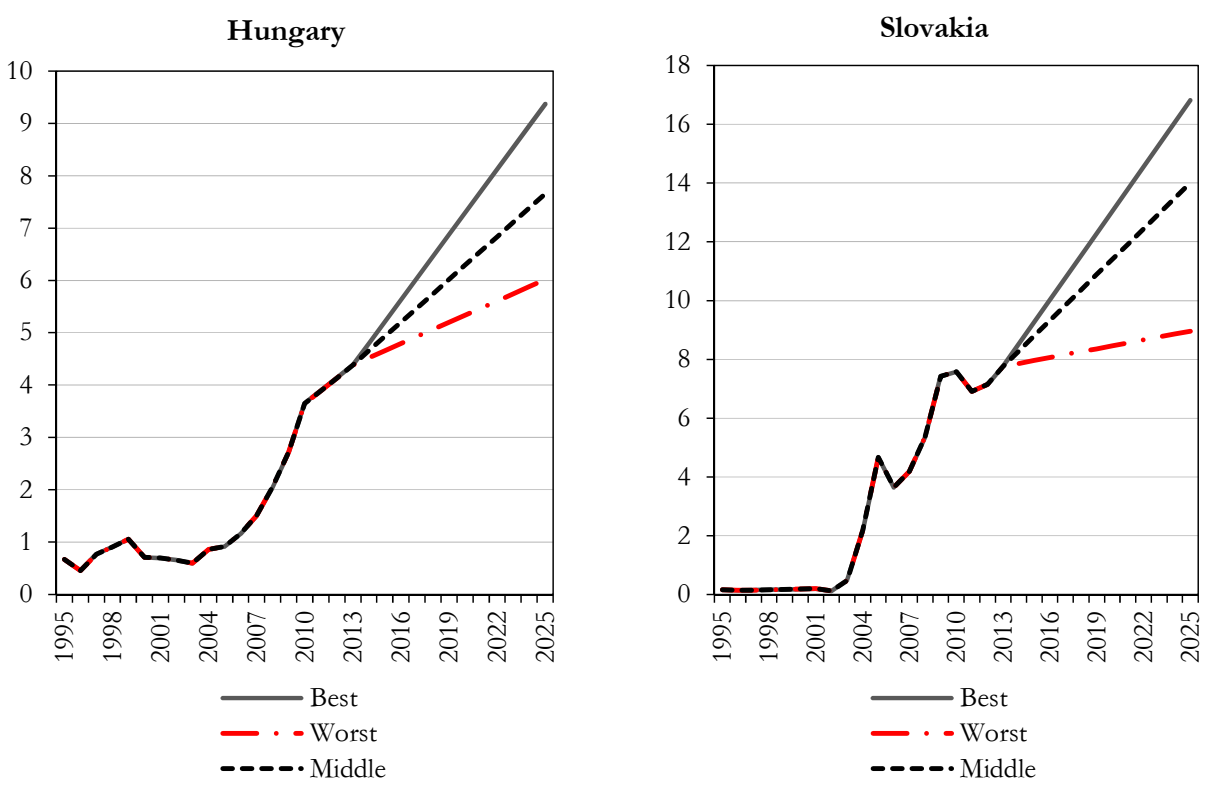

Source: WDI and own calculations.

Regional Statistics, Vol 5, No 2. 2015: 125-143; DOI: 10.15196/RS05207 
In food availability (indicator 3) there is no major difference between the two countries, and the tendencies are also quite similar. In forest lands (indicator 4) Slovakia has a relatively much higher advantage $(24.5 \%$ compared to $40.5 \%)$, but this is largely due to the natural endowments. The historical data of freedom level (indicator 5) does not show relevant differences in the two countries. The future prospects are also similar, although Hungary's political rights rating has declined from 1 to 2 recently.

The differences in GDP per capita (indicator 6) were already mentioned in the Introduction. Slovakia has had a relatively more dynamic economy, and thus, our experts have assigned a higher likelihood to the positive scenario in the case of Slovakia than in the case of Hungary.

In energy efficiency (indicator 7) Hungary has an advantage over Slovakia, and will continue to have the advantage according to our extrapolations. In intentional homicides, infant mortality and internet users (indicators 8-10), there are no major differences between the two countries. These indicators are expected to slowly improve over the 2015-25 period.

The current level of corruption (as measured by the Transparency International surveys, indicator 11) is the same in Hungary and Slovakia, and the future trends are also similar. A slight improvement is expected in both countries. Corruption is a major problem in the region, and because it is influenced strongly by cultural characteristics (Réthi 2012), corruption levels can only be expected to change in the very long term.

Life expectancy at birth (indicator 12) has caused one of the biggest problems for Hungary. Slovakia is not performing better either (by 2025, Hungary and Slovakia can expect to have a life expectancy around 75-77.9 and 75.9-78.4 years, respectively), but Hungary has the lowest life expectancy among the European OECD members and the third lowest among all OECD members. It is largely attributed to the fact that within the OECD, Hungary has the highest mortality rate from cancer and the second highest mortality rate from cardiovascular diseases (OECD 2014).

In literacy rate, refugees displaced from the country and people killed or injured in terrorist attacks (indicators 13-15) the two countries are similar, and the actual and forecasted values are close to the optimal ones. The recent refugee crises and the terrorist attacks are new signs that might prompt more negative scenarios, but the likelihood of those is still very small. Voter turnout (indicator 16) is higher in Hungary. Turnout is an important indicator, and the fact that it is higher in Hungary, definitely gives it an advantage over Slovakia; however, it is also an indicator that is highly volatile and difficult to predict. 
Figure 5

Number of physicians per 1,000 inhabitants in Hungary and Slovakia
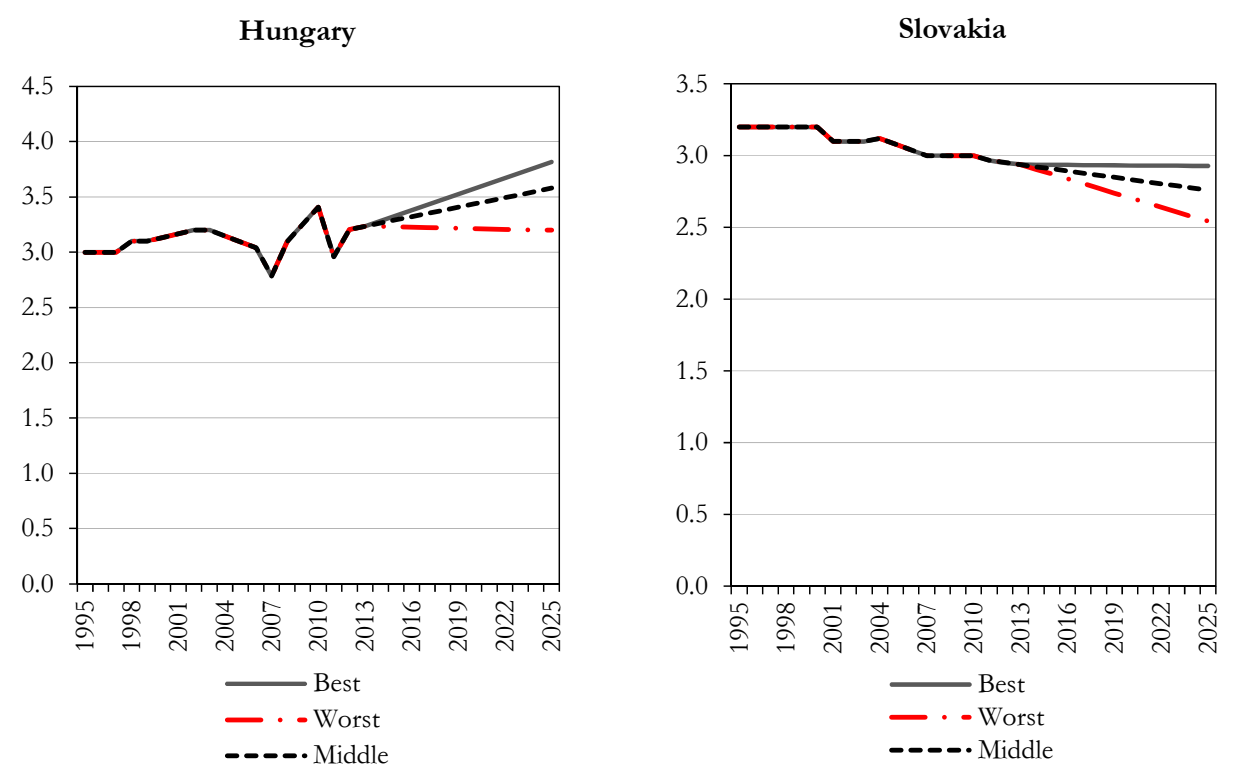

Source: WDI and own calculations.

Hungary has more physicians per 1,000 inhabitants (3.23) than Slovakia (2.94). Another difference is that the Hungarian value is quite variable, which implies that its future path is basically impossible to predict, while the Slovakian value shows a very clear, decreasing trend (Figure 5). The wage difference between the Western and Eastern parts of the European Union and the on-going East-West flow of physicians are significant threats to both countries, although our analysis shows that Slovakia's outlook is worse.

Both countries are predicted to have a negative population growth (indicator 18) in the future. The share of population lacking access to improved water sources (indicator 19) is minimal in both countries, and the poverty headcount ratio (indicator 20) also shows a favourable picture. Poverty, however, is a problem in Hungary as well as in Slovakia. The reason why there are no warning signs within the standard SOFI environment is that the measurement method (people living on less than 1.25 USD per day), is not relevant for the region. According to OECD statistics, the poverty rate is increasing in both Hungary and Slovakia (OECD). In HIV prevalence (indicator 21) the countries are performing well, and although there are some warning signs, no major changes are expected in this field.

Slovakia has quite a terrible score in R\&D expenditure (indicator 22). While Hungary's score is also not favourable compared to other European countries, it is 
still almost twice as high in per GDP terms. According to our extrapolation and experts, Hungary will continue to have an advantage: the 2025 R\&D expenditure per GDP is expected to be in the range of 1.4-2.2 in Hungary and 0.8-1.5 in Slovakia.

Secondary school enrolment (indicator 23) again shows a favourable picture. The share of seats held by women in the national parliament (indicator 24) is traditionally low in the region and is the lowest in Hungary.

The government debt/GDP ratio (indicator 25) is another area where Slovakia dominates Hungary ( $80 \%$ vs. $50 \%$ ). The tendencies, however, are quite different. Hungary's debt ratio has been stagnant, and as economic growth kicks in, it can decrease at a significant pace. Slovakia's debt ratio, on the other hand, has escalated after the 2008 crisis. According to the best-worst scenarios, Hungary could have a lower ratio by 2025. The stability programme put forward by the Slovakian Ministry of Finance in April 2015, however, suggests that the Slovakian debt ratio has stabilised and will slightly decrease in the 2015-18 period (MoFSK 2015, pp. 29).

A considerable difference can be detected in the unemployment levels (indicator 26) as well. Hungary's unemployment level is around 6.5\%, while Slovakia's is almost $11 \%$. The difference is largely due to the major public employment programme started in Hungary. The high unemployment levels are partially caused by the unfavourable structure of labour supply and a high proportion of uneducated labour force. Unemployment is highest among the Romani: the employment rate among them is 15\% in Slovakia and 23\% in Hungary (Gál 2012).

\section{Conclusions}

One of the standard methods to measure the standard of living in a country is the per capita GDP. In this respect, Hungary had an advantage over Slovakia in the 1990s, which slowly evaporated, and by the 2010s, Slovakia was dominating. However, after the 2009 Stiglitz-Sen-Fitoussi report, it has become even more important to find other measures for the well-being of a country. The SOFI methodology presented in this study is in line with most of the principles of the 2009 report. Moreover, this method can be used to predict future well-being. Some of the variables, however, are not relevant for the Central and Eastern European region (notably indicators 3, 10, 14, 15 and 21), or the use of a different indicator would give us a clearer picture about the trends (e.g. indicators 1, 4, 8, 13 and 20). Thus, an analysis conducted with a different set of indicators could lead to even more accurate results. Indicators measuring inequality, deprivation, habitat conditions, the nutrition structure, the acquired skills, the ratio of certain products and services in the budget of an average household and so on would be the ones that are worth discussing as better replacements for the already existing measures.

In our SOFI analysis, we found that Hungary did not have an advantage in the 1990s over Slovakia. In fact, Slovakia was ahead, and Hungary was able to catch up

Regional Statistics, Vol 5, No 2. 2015: 125-143; DOI: 10.15196/RS05207 
around the millennium. After that, Slovakia pulled ahead again, and our analysis suggests that it will continue to do so in the 2015-25 period as well. The comparison highlighted a few areas where Hungary had or will have an advantage over Slovakia, as well as those, where considerable improvement is needed for Hungary. The most important of these areas are the following:

1. Life expectancy at birth: Hungary has the lowest life expectancy among European OECD members, and there is slow improvement in this field. The rate of change is way too slow.

2. Per capita GDP: Slovakia grew 1.4\%/year faster than Hungary in this respect, and that enabled the former to pull way ahead. A change of trends is needed if Hungary wants to catch up. However, our experts did not give much likelihood to the positive scenario that would allow this to happen.

3. Use of renewable energy sources: Hungary is lagging behind, and the recent changes in the Hungarian regulation makes it likely that the distance is going to further increase between the two countries.

4. $\mathrm{CO}_{2}$ emission: Slovakia has an advantage both because of the different size of the two economies and because of the more favourable energy mix.

5. Government debt/GDP: An interesting area for Hungary to concentrate on, as during the 1995-2015 period, Slovakia had a much more favourable ratio, although the advantage seems to be evaporating.

Notable areas where the advantage lies with Hungary:

1. R\&D expenditure per GDP: Even though Hungary's ratio is way behind the European targets, it is still almost twice as high as it is in Slovakia.

2. Unemployment rate: Hungary is among the top performers in Europe as far as the unemployment rate is concerned. However, it is worth mentioning that its current value is largely due to the public employment programme, and the programme's sustainability is questionable.

3. Voter turnout: This is a highly volatile indicator, but Hungary has been consistently having higher turnouts than Slovakia. Thus, the Hungarian electorate seems to be more involved in public affairs.

4. Physicians per inhabitants: There is not a huge difference between the two countries with regard to this area. However, Slovakia's trend shows a consistent and slow drop, while Hungary's time series is variable.

In some areas, both countries have scope for improvement. Demography (population change) and the level of corruption seem to be the most important ones. 


\section{REFERENCES}

ANDERSEN, C. (2015): Climate change performance of Slovakia, Poland, Hungary, Belorus and Ukraine htt://climatepositions.com/update-climate-finance-as-share-of-climate-debt-bycountry/ (downloaded: Dec 2015).

ARPASI, M. (2003): Geothermal development in Hungary - country update report 2000-2002. Geothermics 32 (4-6): 371-377.

BARTHA, Z. - TÓthNÉ, K. SZ. (2015): SOFI Results: Hungary. In: KOLOS, N. - JuTKIEWICZ, P. (eds.): V4 State of the Future Index pp. 13-19., Polish Society for Futures Studies, Warsaw.

GÁL, Zs. (2012): Hungary's Past - Slovakia's Future? CENAA Working Paper http://cenaa.org/en/wp-content/uploads/2012/12/Zsolt-Gal-analysis-final.pdf (downloaded: Dec 2015).

GÁSPÁR, T. (2013): A társadalmi-gazdasági fejlettség mérési rendszerei Statisz̨iteai Sẓmle 91 (1): 78-92.

Glenn, J. C. - Florescu, E. (2015): 2015-16 State of the Future The Millennium Project, Washington DC.

Glenn, J. C. - Gordon, T. J. (2001): 2001 State of the Future The Millennium Project, Washington DC.

KÁDÁRNÉ, H. A. (2013): Áttekintés Magyarország végső energiafelhasználásának alakulásáról Magyar Energetika 20 (6): 27-31.

KLINEC, I. (2015): SOFI Results: Slovakia In: Kolos, N. - JuTKIEWICZ, P. (eds.): V4 State of the Future Index pp 29-34., Polish Society for Futures Studies, Warsaw.

Kolos, N. (2015): V4 SOFI Analysis - methodological approach In: Kolos, N. JutkiewicZ, P. (eds.): V4 State of the Future Index pp 8-12., Polish Society for Futures Studies, Warsaw.

Ministry of ECONOMY OF THE Slovak Republic (MOES) (2014): New version Energy Policy of the Slovak Republic http://www.economy.gov.sk/energy-policy-of-the-slovakrepublic_october-2014-qci/145533s (downloaded: Dec 2015)

Ministry of FinANCE OF THE SlOvAK RepubliC (MOFSK) (2015): Stability Programme of the Slovak Republic for 2015-2018

http://www.finance.gov.sk/en/Components/CategoryDocuments/s_LoadDoc ument.aspx? categoryId $=347 \&$ documentId $=650$ (downloaded: Dec 2015).

OECD (2014): Health Statistics 2014 - How does Hungary compare? http://www.oecd.org/els/health-systems/Briefing-Note-HUNGARY-2014.pdf (downloaded: Dec 2015).

Rethi, G. (2012): Relation Between Tax Evasion and Hofstede's 4+2 Model European Journal of Management 12 (3): 61-72.

SikulovÁ, I. - FranK, K. (2013): Large-Scale Transformation of Socio-Economic Institutions Comparative Case Studies on CEECs Background Paper 1: Comparative Country Study - Slovakia. WWW forEurope Working Paper no 17., Bratislava.

Stiglitz, J.E. - SEN, A. - FitOussi, J-P. (2009): Report by the Commission on the Measurement of Economic Performance and Social Progress www.stiglitz-sen-fitoussi.fr (downloaded: Dec 2015).

Regional Statistics, Vol 5, No 2. 2015: 125-143; DOI: 10.15196/RS05207 


\section{DATA SOURCES}

EIA, US Energy Information Administration: http://www.eia.gov/

Eurostat: http://ec.europa.eu/eurostat/data/database

Freedom House: https://freedomhouse.org/report/freedom-world/freedom-world-2015\#. VmQASeKbEVc

HNEO, Hungarian National Election Office: http://valasztas.hu/

IDEA, International Institute for Democracy and Electoral Assistance: http://www.idea.int/resources/databases.cfm

IF, Pardee Center for International Futures at the University of Denver - International Futures forecasting system: http://pardee.du.edu/access-ifs

IMF-WEO, International Monetary Fund - World Economic Outlook: http://www.imf.org/external/pubs/ft/weo/2015/01/weodata/index.aspx

OECD, Organisation for Economic Co-operation and Development- iLibrary: http://stats.oecd.org/Index

UNDP, United Nations Development Programme - Human Development Reports: http://hdr.undp.org/en/content/human-development-index-hdi-table

WDI, World Bank World Development Indicators: http:/ /databank.worldbank.org/data/reports.aspx?source=world-developmentindicators

WHO, World Health Organisation: http://www.who.int/gho/database/en/ 